УДК 541.128.66.096.3:661.183.6

КИСЛОТНЫЕ И КАТАЛИТИЧЕСКИЕ СВОЙСТВА

БИМЕТАЛЛИЧЕСКИХ КАТАЛИЗАТОРОВ

НА ОСНОВЕ ЦЕОЛИТА ТИПА ZSM-5 В ОБЛАГОРАЖИВАНИИ

ПРЯМОГОННОЙ БЕНЗИНОВОЙ ФРАКЦИИ

\title{
ACID AND CATALYTIC PROPERTIES OF BIMETALLIC \\ CATALYSTS ON THE BASIS OF ZSM-5 TYPE ZEOLITE \\ IN THE REFINING OF STRAIGHT-RUN GASOLINE
}

С.Э. Мирзалиева, А.З. Мамедова, С.М. Ширинова, С.Э. Мамедов, Н.Ф. Ахмедова

Бакинский государственный университет Азербайджанский государственный университет нефти и промышленности Баку, Азербайджанская Республика

Sakina E. Mirzaliyeva, Ayten Z. Mamedova, Susen M. Shirinova, Sabit E. Mammadov, Nargiz F. Akhmedova

Baku State University Azerbaijan State Oil and Industry University, Baku, Republic of Azerbaijan e-mail: n_akhmed@mail.ru

Аннотация. Исследованы кислотные и каталитические свойства цеолита ZSM-5, модифицированного переходными металлами ( $\mathrm{Fe}, \mathrm{Cu}, \mathrm{Ni}, \mathrm{Zn})$ и фосфором в процессе облагораживания прямогонной бензиновой фракции при отсутствии водорода. Показано, что введение в цеолит железа в количестве 1,0-3,0 \% масс., в основном, увеличивает его ароматизирующую активность. Модифицирование Fe-HZSM-5 фосфором приводит к 
увеличению выхода жидких продуктов превращения прямогонных бензиновых фракций. Модифицирование Fe-содержащего катализатора фосфором незначительно изменяет содержание изопарафиновых и ароматических углеводородов в катализате. Изменение каталитических свойств монометаллического Fe-содержащего катализатора существенно зависит от природы и концентрации второго модифицирующего металла. Модифицирование $\mathrm{Fe}$-содержащего цеолита $\mathrm{Cu}$ и $\mathrm{Zn}$ в количестве до 1,0 \% масс. способствует увеличению его изомеризующей активности. Наибольшее содержание изопарафиновых углеводородов на биметаллическом $\mathrm{Ni}-\mathrm{Fe}-$ содержащем катализаторе достигается при содержании никеля, равном 0,5 \% масс. При определенном соотношении модификаторов можно изменять углеводородный состав катализатора и выход жидких продуктов в желаемую сторону. Среди исследуемых биметаллических катализаторов лучшим оказался катализатор состава 0,5 \% Ni 3 \% Fe-2 \% P-HZSM-5, который позволяет при температуре $380{ }^{0} \mathrm{C}$ получать компонент бензина с октановым числом, равным 87, и выходом жидкого катализата 79,1%. Установлено, что изменение каталитических свойств катализаторов в результате модифицирования связано с перераспределением кислотных центров: снижением концентрации сильных бренстедовских центров, образованием более сильных льюисовских кислотных центров типа $\mathrm{Me}^{\mathrm{n}+}-\mathrm{O}^{-}$и металлических центров, участвующих в реакциях изомеризации н-парафиновых и дегидрирования нафтеновых углеводородов, входящих в состав прямогонной бензиновой фракции.

Abstract. The acidic and catalytic properties of ZSM-5 zeolite modified with transition metals $(\mathrm{Fe}, \mathrm{Cu}, \mathrm{Ni}, \mathrm{Zn})$ and phosphorus in the process of refining a straight-run gasoline fraction in the absence of hydrogen were researched. It was shown that the introduction of iron into the zeolite in the amount of 1.0-3.0 wt. \% basically increases its aromatizing activity. Modifying Fe-HZSM-5a with phosphorus leads to an increase in the yield of liquid products of the conversion of straight-run gasoline fractions. Modification of the 
Fe-containing catalyst with phosphorus slightly changes the content of isoparaffin and aromatic hydrocarbons in the catalyzate. The change in the catalytic properties of the monometallic Fe-containing catalyst substantially depends on the nature and concentration of the second modifying metal. Modification of Fe-containing zeolite $\mathrm{Cu}$, and $\mathrm{Zn}$ in an amount of up to $1.0 \mathrm{wt}$. \% contributes to an increase in its isomerizing activity. The highest content of isoparaffin hydrocarbons on the bimetallic Ni-Fe-containing catalyst is achieved with a nickel content of 0.5 wt. \%. At a certain ratio of modifiers, it is possible to change the hydrocarbon composition of the catalyst and the yield of liquid products in the desired direction. Among the studied bimetallic catalysts, the catalyst of composition $0.5 \% \mathrm{Ni} 3 \% \mathrm{Fe}-2 \% \mathrm{P}-\mathrm{HZSM}-5$ turned out to be the best, which allows to obtain a component of gasoline at a temperature of $380{ }^{\circ} \mathrm{C}$ with an octane number equal to 87 and with yield of liquid catalyzate $79.1 \%$. It has been established that a change in the catalytic properties of catalysts as a result of the modification is associated with the redistribution of acid sites: a decrease in the concentration of strong Bronsted centers, the formation of stronger Lewis acid sites $\mathrm{Me}^{\mathrm{n}+}-\mathrm{O}$ type and the metal centers involved in the isomerization reactions of $\mathrm{n}$ paraffin and dehydrogenation of naphthenic hydrocarbons entering in the composition of straight-run gasoline fraction.

Ключевые слова: биметаллические катализаторы, прямогонная бензиновая фракция, бренстедовские и льюисовские кислотные центры

Key words: bimetallic catalysts, the refining of straight-run gasoline, Bronsted and Lewis acid centers

\section{Введение}

Одной из важных задач нефтеперерабатывающей промышленности является переработка прямогонных бензиновых фракций в высокооктановые компоненты моторных топлив с использованием каталитических процес- 
сов с широким использованием моно- и бифункциональных катализаторов $[1,2]$. Среди этих процессов каталитический риформинг является главным процессом переработки, позволяющим получить высокооктановые компоненты моторных топлив и индивидуальные ароматические углеводороды [4-7]. Однако эти катализаторы обладают рядом недостатков: использование дорогостоящих компонентов, невысокая термическая стабильность, необходимость проведения сложной регенерации, протекание процесса под давлением водорода, значительные энергетические затраты. Всё это обуславливает поиск и разработку более дешёвых и высокоэффективных катализаторов, не содержащих благородных металлов, а также принципиально новых условий протекания реакций риформинга.

Перспективным процессом для получения высокооктановых моторных топлив является облагораживание прямогонных бензиновых фракций в отсутствии водорода в присутствии бифункциональных катализаторов на основе цеолита типа ZSM-5.

Цеолиты типа ZSM-5 проявляют необычные адсорбционные, молекулярно-ситовые и каталитические свойства. В цеолите ZSM-5 поры представлены прямыми и «синусоидальными» каналами. Прямые каналы имеют в сечении форму правильного круга $(0,54 \times 0,56$ нм) [8]. Средний диаметр пор этих цеолитов таков, что препятствует образованию углеводородов с числом атомов углерода в молекуле большим, чем 12, что обеспечивает высокую селективность процесса превращения парафиновых углеводородов и нафтеновых углеводородов, входящих в состав бензиновых фракций. Селективность бифункциональных катализаторов на основе цеолитов зависит от соотношения их кислотной и гидро-дегидрирующей функций $[4,6,9]$.

В работах $[6,10,11]$ исследовано влияние различных модифицирующих элементов на каталитические свойства пентасилов в процессе облагораживания прямогонной бензиновой фракции. Биметаллические катализаторы на основе пентасилов (Pt-Zn, $\mathrm{Pt}-\mathrm{Ga}, \mathrm{Cu}-\mathrm{Cd}, \mathrm{Zr}-\mathrm{Ga})$ проявили более 
высокую активность и селективность в процессе повышения октанового числа (ОЧ) прямогонных бензиновых фракций [6, 12, 13].

Целью настоящей работы явилось изучение влияния природы и концентрации переходных металлов (Fe, $\mathrm{Zn}, \mathrm{Cu}, \mathrm{Ni})$ и фосфора на кислотные и каталитические свойства цеолита типа ZSM-5 в процессе облагораживания прямогонной бензиновой фракции.

\section{Экспериментальная часть}

В качестве исходного был выбран цеолит типа ZSM-5 с $\mathrm{SiO}_{2}: \mathrm{Al}_{2} \mathrm{O}_{3}$ = 61. Н-форму цеолита получали по методике, описанной в [6]. Катализаторы, модифицированные железом и фосфором, получали следующим способом: цеолит в Н-форме прибавляли к раствору золя оксида алюминия. Далее готовили раствор гексаметилентетрамина и к нему прибавляли гидрофосфат аммония в таком количестве, чтобы содержание фосфора в катализаторе составляло 1,0-2,0 \% масс. Этот раствор прибавляли к смеси цеолит/золь оксида алюминия. Затем смесь диспергировали в масляной бане при $90{ }^{0} \mathrm{C}$ и выдерживали в этой бане при температуре $150{ }^{0} \mathrm{C}$ до образования гидрогеля. Сферы гидрогеля удаляли из бани, промывали 1,0%-ым водным раствором аммиака, сушили на воздухе и прокаливали при $550{ }^{0} \mathrm{C}$ в течение 4 ч. Прокаленные сферы пропитывали в растворе нитрата железа в расчете на 1,0-3,0 \% масс. железа в составе катализатора. Образец сушили на воздухе и прокаливали при $500{ }^{0} \mathrm{C}$ в течение 4 ч. Биметаллические катализаторы получали пропитыванием железосодержащих образцов растворами нитратов цинка, никеля и меди в расчете на 0,5-1,5 \% масс. модификатора в составе катализатора. После этого катализаторы подвергали сушке и прокаливанию. Все приготовленные образцы содержали $25 \%$ масс. связующего - $\mathrm{Al}_{2} \mathrm{O}_{3}$.

Превращения прямогонной бензиновой фракции исследовали на установке проточного типа с кварцевым реактором со стационарным слоем катализатора. Опыты проводили при температуре $350-430{ }^{0} \mathrm{C}$ с 10 мл катали- 
затора с объёмной скорости подачи сырья 2 ч $^{-1}$. Продукты реакции анализировали хроматографическим методом. Условия анализа описаны в работе [6]. В качестве сырья была выбрана прямогонная бензиновая фракция с Бакинского нефтеперерабатывающего завода Азерияг.

Характеристики прямогонной фракции представлены в таблице 1.

Таблица 1. Характеристики прямогонной фракции

\begin{tabular}{|l|c|l|c|}
\hline \multicolumn{2}{|c|}{ Плотность при $20{ }^{0} \mathrm{C}$, кг/ ${ }^{3}$} & \multicolumn{2}{c|}{757} \\
\hline Фракционный состав, ${ }^{0} \mathrm{C}$ & \multicolumn{2}{c|}{ Углеводородный состав, \% масс. } \\
\hline $10 \%$ & 82 & парафиновые & 28,3 \\
\hline $50 \%$ & 98 & изопарафиновые & 29,5 \\
\hline $90 \%$ & 113 & нафтеновые & 33,4 \\
\hline к.к & 148 & ароматические & 8,8 \\
\hline
\end{tabular}

\section{Результаты и их обсуждение}

Из таблицы 2 видно, что при использовании немодифицированного HZSM-5 с увеличением температуры реакции с $350{ }^{0} \mathrm{C}$ до $430{ }^{\circ} \mathrm{C}$ выход жидких продуктов снижается с 71,8 \% до 64,2%, а ароматических углеводородов возрастает с 10,6 \% до 16,7 \%. На этом образце в исследуемом интервале температур выход изопарафиновых углеводородов проходит через максимум, причём при температуре реакции $380{ }^{\circ} \mathrm{C}$ по отношению к исходному сырью содержание изопарафинов возрастает всего на 3 \%, октановое число катализата возрастает с 58 для сырья до 74. Модифицирование HZSM-5железом приводит к увеличению содержания в катализате высокооктановых компонентов: изопарафиновых и ароматических углеводородов. Увеличение концентрации железа в цеолите с 1,0 \% масс. до 3,0 \% масс. приводит к возрастанию содержания ароматических углеводородов. Например, при $380{ }^{0} \mathrm{C}$ увеличение содержания железа до 3,0 \% масс. содержание ароматических углеводородов возрастает с 14,8 \% масс. до 
24,8 \% масс. Следует отметить, что при модифицировании HZSM5железом заметно возрастает выход изопарафиновых углеводородов (с 33,5 \% до 36,2 \%). Октановое число катализата по ИМ возрастает до 81,3.

Таблица 2. Превращение прямогонных бензиновых фракций на биметаллических катализаторах

\begin{tabular}{|c|c|c|c|c|c|c|c|}
\hline \multirow{2}{*}{$\begin{array}{c}\text { № } \\
\text { образца }\end{array}$} & & \multirow{2}{*}{$\begin{array}{l}\mathbf{T}, \\
{ }^{\circ} \mathbf{C}\end{array}$} & \multirow{2}{*}{$\begin{array}{c}\text { Выход } \\
\text { жидких } \\
\text { продуктов, } \\
\text { \% масс. }\end{array}$} & \multicolumn{4}{|c|}{$\begin{array}{c}\text { Углеводородный состав жидких } \\
\text { продуктов, \% масс. }\end{array}$} \\
\hline & & & & Пр.У+Наф.У & і-Пр.У & Ол. & APY \\
\hline \multirow{3}{*}{1.} & \multirow{3}{*}{ HZSM-5 } & 350 & 71,8 & 57,7 & 30,5 & 1,2 & 10,6 \\
\hline & & 380 & 68,4 & 50,2 & 33,5 & 1,5 & 14,8 \\
\hline & & 430 & 64,2 & 49,6 & 26,7 & 3,0 & 16,7 \\
\hline \multirow{3}{*}{2.} & \multirow{3}{*}{$1 \%$ Fe-HZSM-5 } & 350 & 72,4 & 52,3 & 30,9 & 0,9 & 15,9 \\
\hline & & 380 & 69,5 & 41,8 & 34,2 & 1,2 & 22,8 \\
\hline & & 430 & 64,8 & 38,8 & 31,1 & 2,0 & 28,1 \\
\hline \multirow{3}{*}{3.} & \multirow{3}{*}{$3 \%$ Fe-HZSM-5 } & 350 & 70,3 & 44,6 & 31,8 & 0,8 & 18,1 \\
\hline & & 380 & 66,6 & 37,9 & 36,2 & 1,1 & 24,8 \\
\hline & & 430 & 62,7 & 33,7 & 35,2 & 1,8 & 29,4 \\
\hline \multirow{3}{*}{4.} & \multirow{3}{*}{$3 \% \mathrm{Fe}-1 \% \mathrm{P}-\mathrm{HZSM}-5$} & 350 & 75,8 & 47,1 & 32,9 & 0,8 & 19,2 \\
\hline & & 380 & 74,1 & 35,7 & 37,8 & 0,9 & 25,6 \\
\hline & & 430 & 70,8 & 32,3 & 35,8 & 1,7 & 30,2 \\
\hline \multirow{2}{*}{5.} & \multirow{2}{*}{$3 \% \mathrm{Fe}-2 \% \mathrm{P}-\mathrm{HZSM}-5$} & 380 & 77,4 & 35,5 & 38,5 & 0,9 & 25,1 \\
\hline & & 430 & 75,2 & 33,8 & 36,1 & 1,4 & 28,7 \\
\hline \multirow{2}{*}{6.} & \multirow{2}{*}{$0,5 \% \mathrm{Cu} 3 \% \mathrm{Fe}-2 \% \mathrm{P}-\mathrm{HZSM}-5$} & 380 & 78,4 & 34,6 & 39,9 & 0,6 & 24,9 \\
\hline & & 430 & 76,8 & 33,0 & 37,1 & 1,2 & 28,7 \\
\hline \multirow{2}{*}{7.} & \multirow{2}{*}{$1,0 \% \mathrm{Cu} 3 \% \mathrm{Fe}-2 \% \mathrm{P}-\mathrm{HZSM}-5$} & 380 & 79,4 & 32,1 & 41,8 & 0,5 & 25,6 \\
\hline & & 430 & 77,1 & 31,9 & 38,6 & 0,7 & 28,8 \\
\hline \multirow{2}{*}{8.} & \multirow{2}{*}{$0,5 \% \mathrm{Zn} 3 \% \mathrm{Fe}-2 \% \mathrm{P}-\mathrm{HZSM}-5$} & 380 & 77,3 & 34,2 & 38,4 & 0,8 & 26,6 \\
\hline & & 430 & 75,1 & 33,3 & 36,5 & 1,1 & 29,1 \\
\hline
\end{tabular}

Примечание.

Пр.У - парафиновые углеводороды; Наф.У - нафтеновые углеводороды; Ол. - олефины; АРУ - ароматические углеводороды.

Модифицирование Fe-HZSM-5а фосфором приводит к увеличению выхода жидких продуктов превращения прямогонных бензиновых фракций. На образце 4, содержащем 1,0 \% масс. фосфора $\left(380{ }^{\circ} \mathrm{C}\right)$, выход жидких углеводородов возрастает до 74,1 \%, а содержание изопарафиновых и ароматических углеводородов изменяется незначительно. При увеличении содержания фосфора в катализаторе до 2,0 \% масс. (обр. 5) выход жидких продуктов возрастает до 77,4 \%. 
Модифицирование образца катализатора 3 \% Fe + 2 \% P/HZSM-5 медью существенно повышает содержание изопарафиновых углеводородов в катализате. Максимальное содержание изопарафиновых углеводородов достигается на катализаторе 7 , содержащем $1,0 \%$ меди и достигает до $41,8 \%$ масс. Октановое число катализата, полученного при $380{ }^{\circ} \mathrm{C}$ на образце 7 , составляет 86 . Увеличение содержания меди в катализаторе до 1,5 \% неблагоприятно влияет на выход изопарафиновых углеводородов.

Селективность изомеризации и ароматизации зависит также от концентрации и природы модифицирующего металла. Как видно из рисунка 1 , увеличение концентрации цинка и меди в катализаторе $3,0 \% \mathrm{Fe} 2,0 \%$ P/HZSM-5 (обр. 5) до 1,0 \% масс. способствует возрастанию выхода изопарафиновых углеводородов до 40,2 \% масс. и 41,8 \% масс. соответственно. Дальнейшее увеличение концентрации цинка и меди заметно снижает изомеризующую активность катализатора. Однако модифицирование $\mathrm{Fe}$ содержащего катализатора (обр. 5) малым количеством никеля (0,5 \% масс.) приводит к резкому росту выхода изопарафиновых углеводородов. На этом образце содержание изопарафиновых углеводородов достигает до 42,5 \% масс., а октановое число катализата возрастает до 87,0. Дальнейшее увеличение концентрации никеля снижает содержание изопарафиновых и увеличивает содержание ароматических углеводородов в катализате. По изомеризующей селективности биметаллические цеолитные катализаторы располагаются в ряд:

Ni-Fe-P/HZSM-5 > Cu-Fe-P/HZSM-5 > Zn-Fe-P/HZSM-5. 

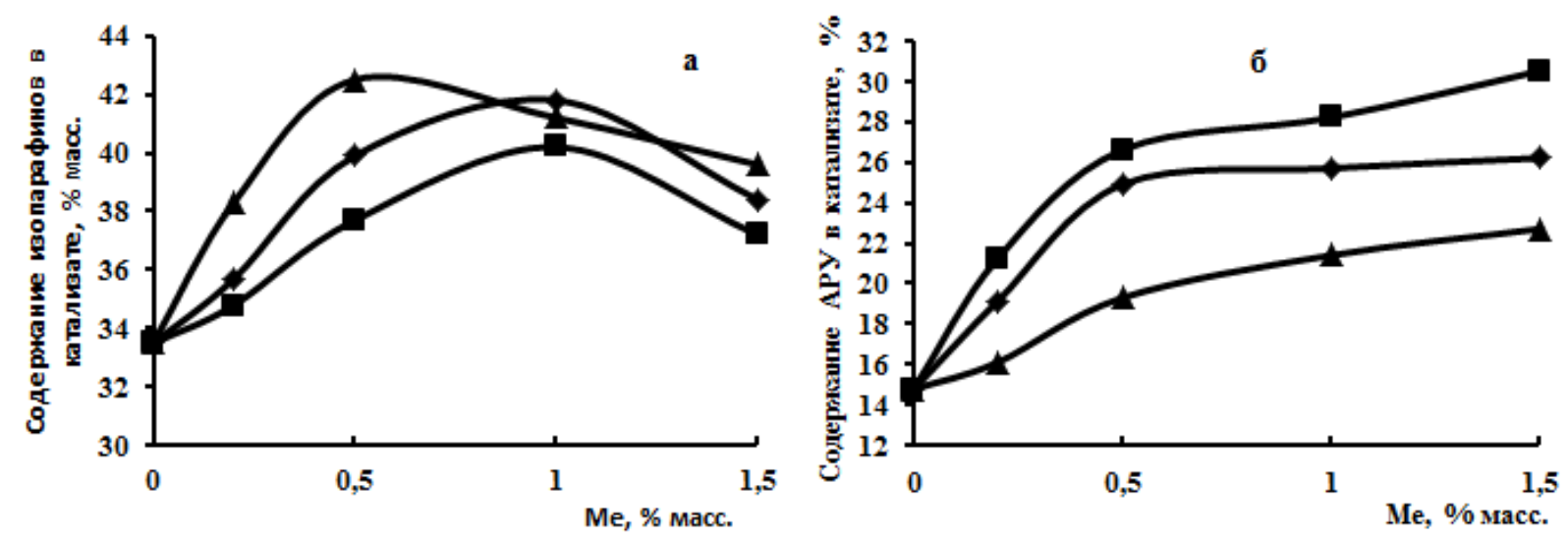

Рисунок 1. Зависимость содержания изопарафинов (а) и АРУ (б) в катализате от концентрации металла в катализаторе

Модифицирование 3,0 \% Fe 2,0 \% P/HZSM-5 (обр. 5) модификаторами существенно повышает также содержание ароматических углеводородов в катализате. Наибольшую ароматизирующую активность проявляют образцы, модифицированные цинком. Увеличение концентрации цинка до 1,5 \% масс. приводит к возрастанию выхода ароматических углеводородов до 30,5 \% масс. По ароматизирующей селективности биметаллические цеолитные катализаторы располагаются в ряд:

\section{Zn-Fe-P/HZSM-5 > Cu-Fe-P/H > Ni-Fe-P/HZSM-5.}

По-видимому, изменение каталитических свойств пентасилов в результате их модифицирования различными модификаторами ( $\mathrm{Fe}, \mathrm{Cu}, \mathrm{Zn}, \mathrm{Ni})$ связано с существенным снижением концентрации сильных бренстедовских центров типа $\mathrm{Me}^{\delta^{+}}-\mathrm{O}_{\text {реш. }}$, способных к сильной поляризации и активации Н-Н и С-Н связей $[12,14]$ и, тем самым ускорять дегидрирование нпарафиновых и нафтеновых углеводородов.

Для объяснения влияния модифицирования цеолита HZSM-5 переходными металлами на их каталитические свойства в процессе переработки прямогонного бензина были исследованы кислотные характеристики катализаторов методом ТПД аммиака (таблица 2). 
Таблица 2. Кислотные характеристики катализаторов

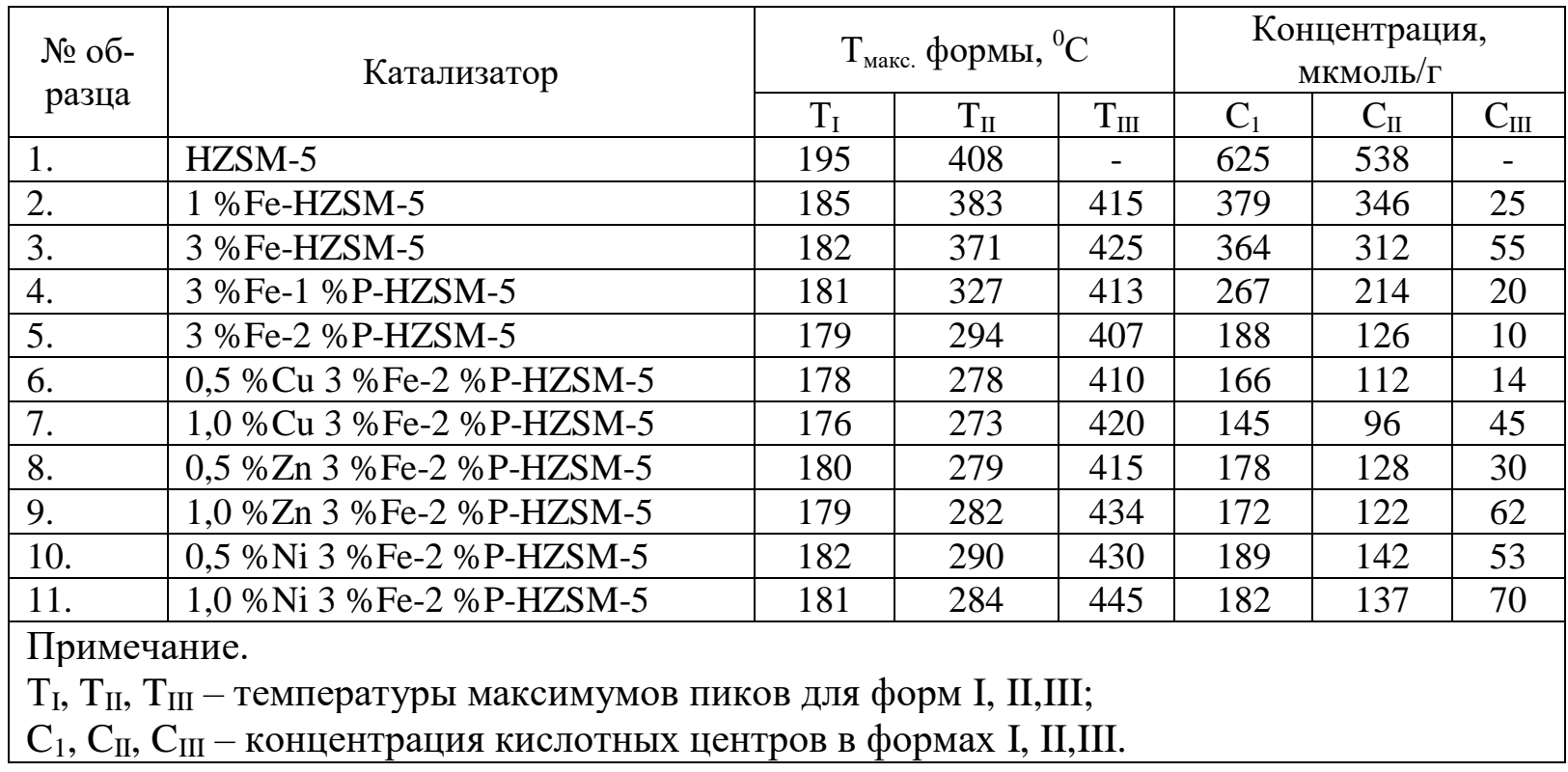

Для исходного цеолита HZSM-5 в ТПД-спектре наблюдаются два пика, что указывает на наличие двух форм десорбции аммиака из цеолитного катализатора: низкотемпературный пик в области $125-250{ }^{\circ} \mathrm{C}$ с температурой максимума пика $\mathrm{T}_{\text {макс. }}=195{ }^{\circ} \mathrm{C}$ относится к десорбции аммиака преимущественно со слабых льюисовких кислотных центров, которыми в HZSM-5 являются координально-ненасыщенные ионы алюминия, и высокотемпературный пик в области $250-450{ }^{0} \mathrm{C}$ с $\mathrm{T}_{\text {макс. }}=408{ }^{\circ} \mathrm{C}$, относящийся к десорбции аммиака преимущественно с сильных бренстедовских центров, которыми являются ионы водорода мостиковых гидроксильных групп $[9,12]$. Концентрация слабокислотных льюисовских кислотных центров для HZSM-5, определенная по количеству десорбированного аммиака, составляет 625, для сильнокислотных центров - 538 мкмоль/г. (таблица 2). После введения в цеолит $\mathrm{Fe}$ сила и концентрация кислотных центров обоих типов снижается, что свидетельствует о взаимодействии бренстедовских кислотных центров самого цеолита с ионами $\mathrm{Fe}^{+3}$. При увеличении концентрации $\mathrm{Fe}$ в цеолите до 3,0\% масс. концентрация сильных кислотных центров снижается до 346 мкмоль/г. Добавка Fе к катализатору HZSM-5 приводит к изменению его кислотных характеристик, что особенно проявляется при более высоком содержании $\mathrm{Fe}$. Так, при ТД-спектрах образца 
(3 \% Fe/HZSM-5) наблюдается проявление третьего пика с высокой энергией удерживания аммиака сильными льюисовскими кислотными центрами, а концентрация кислотных центров высокотемпературной формы несколько выше, чем в катализаторе 1 \% Fe/HZSM-5.

Введение фосфора в состав Fе-содержащего цеолита (обр. 3) приводит к дальнейшему снижению концентрации сильных кислотных центров. Дополнительное модифицирование Fe-P-HZSM-5 (катализатора обр. 5) катализатора $\mathrm{Cu}, \mathrm{Zn}$ и $\mathrm{Ni}$ мало влияет на концентрацию сильных бренстедовских кислотных центров, но существенно увеличивает концентрацию сильных льюисовских кислотных центров. С увеличением содержания модификатора до 1,0 \% масс. происходит возрастание концентрации сильных льюисовских кислотных центров. Наибольшая концентрация сильных льюисовских центров наблюдается на биметаллическом катализаторе, содержащем 1,0 \% масс. Ni. Изменение кислотных свойств цеолитных катализаторов можно объяснить тем, что в процессе приготовления и термической обработки цеолита происходит взаимодействие ионов металлов с гидроксильными группами, в результате чего происходит уменьшение концентрации сильных бренстедовских кислотных центров и образование новых более сильных льюисовских кислотных центров. Кроме того, часть наночастиц металлов и их различных окисленных структур проникают в микропоры цеолита и распределяются по поверхности катализатора, где они с координационно-ненасыщенными ионами Al кристаллической решетки образуют дополнительно льюисовские кислотные центры.

\section{Выводы}

Таким образом, в результате модифицирования цеолита HZSM-5 переходными металлами происходит перераспределение кислотных центров: снижение концентрации сильных кислотных центров и образование сильных льюисовских кислотных центров. 
Основной вклад в каталитическую активность модифицированных цеолитов типа HZSM-5 в изомеризации н-парафинов и дегидрирования нафтеновых углеводородов вносят льюисовские кислотные центры цеолита типа $\mathrm{Me}^{\mathrm{n+}}-\mathrm{O}^{-}$, формирующиеся в результате модифицирования цеолита переходными металлами. Эти центры обладают ярко выраженными поляризующими свойствами по отношению к молекулам н-парафиновых, нафтеновых углеводородов и водорода [12] и ответственны за дегидрирующую активность катализатора в превращениях этих углеводородов. Основная роль бренстедовских кислотных центров состоит в образовании карбкатионов, причём для образования которых, достаточно небольшое число «мостиковых» ОН-групп цеолита.

\section{Список используемых источников}

1. Муниров Т.А., Давлетшин А.Р., Шириязданов Р.Р., Ахметов А.Ф., Хамзин Ю.А., Ганцев А.В., Амангельдиев Д.М. Исследование процесса ароматизации сырья риформинга на цеолитсодержащем катализаторе // Сетевое издание «Нефтегазовое дело». 2018. № 5. С. 58-77.

2. Кузьмина Р.И., Фролов М.П., Ливенцев В.Т., Ветрова Т.К., Ковнев А.В. Разработка цеолитсодержащего катализатора риформинга // Катализ в промышленности. 2010. № 6. С. 29-34.

3. Klerk A. Zeolites as Catalysts for Fuels Refining after Indirect Liquefaction Processes // Molecules. 2018. No. 23 (1). pp. 115-132. DOI: 10.3390/molecules23010115.

4. Ерофеев В.И., Хомяков И.С., Егорова Л.А. Получение высокооктановых бензинов из прямогонных бензинов на модифицированных цеолитах // Теоретические основы химической технологии. 2014. T. 48. № 1. C. 77-82. DOI: 10.7868/S0040357114010023. 
5. Мамедов С.Э., Ахмедова Н.Ф., Мирзалиева С.Э., Мирзаи Дж.И., Ахмедов Э.И., Азмамедова Х.М., Дадашева С.С. Превращение н-гексана и прямогонной бензиновой фракции на модифицированных пентасилах // Нефтегазохимия. 2018. № 1. С. 35-38. DOI: 10.24411/2310-8266-2018-10106.

6. Мамедов С.Э., Ахмедова Х.В., Ахмедова Н.Ф., Дадашева С.С., Ахмедов Э.И. Превращения прямогонной бензиновой фракции на высококремнеземном цеолите, модифицированном галлием и цирконием // Химия и технология топлив и масел. 2016. № 3 (595). С. 28-31.

7. Величкина Л.М., Восмериков А.В., Восмерикова Л.Н., Канашевич Д.А. Влияние структурного типа цеолита на его изомеризующую активность в процессе превращения н-алканов // Нефтепереработка и нефтехимия. Научно-технические достижения и передовой опыт: науч.-информац. сб. М., 2016. № 8. С. 29-36.

8. Baerlocher Ch., McCusker L.B., Olson D.H. Atlas of Zeolite Framework Types. URL: http://www.iza-structure.org/books/Atlas_6ed.pdf (дата обращения: 12.04.2019).

9. Arean C.O., Delgado M.R., Nachtigall P., Thang H.V., Rubeš M., Bulánek R., Chlubná-Eliášová P. Measuring the Brønsted Acid Strength of Zeolites - Does it Correlate with the O-H Frequency Shift Probed by a Weak Base? // Physical Chemistry Chemical Physics. 2014. No. 21 (16). P. 1012910141. DOI: $10.1039 / \mathrm{C} 3 \mathrm{CP} 54738 \mathrm{H}$.

10. Asaftei I.V., Sandu I., Lungu N.C., Spac A.F., Ignat M. Transformation of Gaseous Technical Mixture of the Alkanes and Alkenes into Liquid Fraction over Ni-HZSM-5 Obtained by Ionic Exchange // Revista de chimie. 2018. Vol. 69 (4). P. 938-943.

11. Peron D.V., Zholobenko V.L., de la Rocha M.R., de Souza M.O., Feris L.A., Marcilio N.R., Ordomsky V.V., Khodakov A.Y. Nickel-Zeolite Composite Catalysts with Metal Nanoparticles Selectively Encapsulated in the Zeolitemicropores // Journal of Materials Science. 2019. Vol. 54 (7). P. 53995411. DOI: 10.1007/s10853-018-03250-5. 
12. Kazansky V.B., Borovkov V.Yu., Serikh A.I., van Santen R.A., Anderson B.G. Nature of the Sites of Dissociative Adsorption of Dihydrogen and Light Paraffins in ZnHZSM-5 Zeolite Prepared by Incipient Wetness Impregnation // Catalysis Letters. 2000. Vol. 66. Issue 1-2. P. 39-47. DOI: 10.1023/A\%3A1019031119325.

13. Афонин А.А., Аниськова Т.В., Ветрова Т.К., Ливенцев В.Т., Кузьмина Р.И. Каталитические превращения н-гексана на модифицированном высококремнеземном цеолите // Известия вузов. Серия Химия и химическая технология. 2012. Т. 55. № 5. С. 101-104.

14. Дергачев А.А., Лапидус А.Л. Каталитическая ароматизация низших алканов. URL: http://www.chem.msu.su/rus/jvho/2008-4/15.pdf (дата обращения: 12.04.2019).

\section{References}

1. Munirov T.A., Davletshin A.R., Akhmetov A.F., Shiriyazdanov R.R., Khamzin Yu.A., Gantsev A.V., Amangeldiyev D.M. Issledovaniye protsessa aromatizatsii syrya riforminga na tseolitsoderzhashchem katalizatore [Research of the Raw Material Aromatization Reforming Process on the ZeoliteContaining Catalyst]. Setevoe izdanie «Neftegazovoe delo»-Online Edition «Oil and Gas Business», 2018, No. 5, pp. 58-77. [in Russian].

2. Kuzmina R.I., Frolov M.P., Liventsev V.T., Vetrova T.K., Kovnev A.V. Razrabotka tseolitsoderzhascheqo katalizatora riforminqa [Development of Reforming Zeolite Catalyst ]. Kataliz v promyshlennosti - Catalysis in Industry, 2010, No. 6, pp. 29-31 [in Russian].

3. Klerk A. Zeolites as Catalysts for Fuels Refining after Indirect Liquefaction Processes, 2018, No. 23 (1), pp. 115-132. DOI: 10.3390/molecules23010115. 
4. Erofeev V.I., Khomyakov I.S., Egorova L.A. Poluchenie vysokooktanovykh benzinov iz pryamogonnych benzinov na modifitsirovannych tseolitach. [Production of High-Octane Gasolines from Straight-Run Gasolines on Modified Zeolites]. Teoreticheskie osnovy ximicheskoy texnologii - Theoretical Foundations of Chemical Technology, 2014, Vol. 48, No 1, pp. 77-82. DOI: 10.7868/S0040357114010023 [in Russian].

5. Mamedov S.E., Akhmedova N.F., Mirzaliyeva S.E., Mirzai Dj.I., Akhmedov E.I., Azmamedova H.M., Dadasheva S.S. Prevrashchenie n-geksana I pryamogonnoy benzinovoy fraktsii na modifitsirovannych pentasilach [Transformation of N-Hexane and Straight-Run Gasoline onto Modified Pentasyles]. Neftegazochimiya - Oil and Gas Chemistry, 2018, No 1, pp. 35-38. DOI: 10.7868/S0028242116060186 [in Russian].

6. Mamedov S.E., Akhmedova Ch.V., Akhmedova N.F., Dadasheva S.S., Akhmedov E Prevraschenie pryamoqonnoy benzinovoy fraktsii na vysokokremnezemnom tseolite, modifitsirovannom galliem I tsirkoniem [Transformation of Straight-Run Gasoline Fraction on High-Silica Zeolite Modified by Gallium and Zirconium]. Khimiya i tekhnologiya topliv $i$ masel Chemistry and Technology of Fuels and Oils, 2016, No. 3 (595), pp. 28-31. [in Russian].

7. Velichkina L.M., Vosmerikov A.V., Vosmerikova L.N., Kanashevich D.A. Vliyaniye strukturnoqo tipa tseolita na eqo izomerizuyuschuyu aktivnost $\mathrm{v}$ protsesse prevrascheniya $\mathrm{n}$-alkanov [The Influence of the Structural Type of Zeolite on its Isomerizing Activity in the Process of Transformation of N-Alkanes]. Nauchno-informatsionnyy sbornik «Neftepererabotka I neftekhimiya. Nauchno-tekhnicheskie dostizheniya $i$ peredovoy opyt» [Scientific Information Collection «Oil Refining and Petrochemistry. Scientific and Technical Achievements and Best Practices]. Moscow, 2016, No. 8, pp. 29-36. [in Russian]. 
8. Ch. Baerlocher Lynne B. McCusker D.H. Olson. Atlas of Zeolite Framework Types. 6th Edition. Write a Review. Elsevier Science. Published Date: 7th August 2007. 404 p. Available at: http://www.izastructure.org/books/Atlas_6ed.pdf (accessed 12.04.2019).

9. Arean C.O., Delgado M.R., Nachtigall P., Thang H. V., Rubeš M., Bulánek R., Chlubná-Eliášová P. Measuring the Brønsted Acid Strength of Zeolites - Does It Correlate with the O-H Frequency Shift Probed by a Weak Base? Physical Chemistry Chemical Physics, 2014, No. 21 (16), pp. 1012910141. DOI: $10.1039 / \mathrm{C} 3 \mathrm{CP} 54738 \mathrm{H}$

10. Asaftei I.V., Sandu I., Lungu N.C., Spac A.F., Ignat M. Transformation of Gaseous Technical Mixture of the Alkanes and Alkenes into Liquid Fraction over Ni-HZSM-5 Obtained by Ionic Exchange. Revista de chimie, 2018, Vol. 69(4), pp. 938-943.

11. Peron D.V., Zholobenko V.L., de la Rocha M.R., de Souza M.O., Feris L.A., Marcilio N.R., Ordomsky, V.V., Khodakov A.Y. Nickel-Zeolite Composite Catalysts with Metal Nanoparticles Selectively Encapsulated in the Zeolitemicropores. Journal of Materials Science, 2019, Vol. 54(7). pp. 53995411. DOI: 10.1007/s10853-018-03250-5.

12. Kazansky V.B., Borovkov V.Yu., Serikh A.I., van Santen R.A., Anderson B.G. Nature of the Sites of Dissociative Adsorption of Dihydrogen and Light Paraffins in ZnHZSM-5 Zeolite Prepared by Incipient Wetness Impregnation. Catalysis Letters, 2000, Vol. 66, Issue 1-2. pp. 39-47. DOI: 10.1023/A\%3A1019031119325.

13. Afonin A.A., Aniskova T.V., Vetrova T.K., Liventsev V.T., Kuzmina R.I. Kataliticheskie prevrascheniya n-geksana na modifitsirovannom vysokokremnezemnom tseolite [Catalytic Transformations of N-Hexane on a Modified High-Silica Zeolite]. Izvestiya VUZov. Seriya chimiya i chimicheskaya texnologiya - Russian Journal of Chemistry and Chemical Technology, 2012, Vol. 55, No. 5, pp. 101-104. [in Russian]. 
14. Derqachev A.A., Lapidus A.L. Kataliticheskaya aromatizatsiya nizshich alkanov [Catalytic Aromatization of Lower Alkanes]. URL: http://www.chem.msu.su/rus/jvho/2008-4/15.pdf (accessed 12.04.2019).

\section{Сведения об авторах}

\section{About the authors}

Мирзалиева Сакина Эйлаз гызы, кандидат химических наук, доцент кафедры «Физической и коллоидной химии», Бакинский государственный университет, г. Баку, Азербайджанская Республика

Sakina E. Mirzaliyeva, Candidate of Chemical Sciences, Assistant Professor of Physical and Kolloidal Chemistry Department, Baku State University, Baku, Republic of Azerbaijan

e-mail: mirzaliyeva.s@mail.ru

Мамедова Айтен Закир гызы, кандидат химических наук, доцент кафедры «Технологии и экологии», Азербайджанский государственный университет нефти промышленности, г. Баку, Азербайджан

Ayten Z. Mammadova, Candidate of Chemical Sciences, Assistant Professor of Technology and Ecology Department, Azerbaijan State University of Oil and Industry, Baku, Republic of Azerbaijan

e-mail: ayten1551@mail.ru

Ширинова Сусен Мирзаммед гызы, диссертант кафедры «Физической и коллоидной химии», Бакинский государственный университет, г. Баку, Азербайджан

Susen M. Shirinova, Ph student of Physical and Colloidal Chemistry Department, Baku State University, Baku, Republic of Azerbaijan

e-mail: s_shirinova@mail.ru 
Мамедов Сабит Эюб оглы, доктор химических наук, профессор кафедры «Физической и коллоидной химии», Бакинский государственный университет, г. Баку, Азербайджанская Республика

Sabit E. Mammadov, Doctor of Chemical Sciences, Professor of Physical and Colloidal Chemistry Department, Baku State University, Baku, Republic of Azerbaijan

e-mail: sabitmamedov51@mail.ru

Ахмедова Наргиз Фирудин гызы, кандидат химических наук, научный сотрудник Лаборатории Металлокомплексных катализаторов, Бакинский государственный университет, г. Баку, Азербайджанская Республика

Nargiz F. Akhmedova, Candidate of Chemical Sciences, Researcher of Metal Complex Catalysts Laboratories, Baku State University, Baku, Republic of Azerbaijan

e-mail: n_akhmed@mail.ru 